\section{Alianças e violências nos mundos virtuais}

\section{RESUMO}

Para ilustrar a maneira como certas figuras da violência se comunicam pela Internet, são analisados dois exemplos que renegociam o hiato, sempre explorado nos estudos sobre a rede e os mundos digitais, entre realidade e virtualidade.

\section{ABSTRACT}

This paper analyses two examples which have frequently been explored in studies about digital worlds to illustrate how certain figures of violence communicate through the Internet.

\section{PALAVRAS-CHAVE (KEY WORDS)}

- Comunidades virtuais (virtual communities)

- Violência (violence)

- Segredo (secret)

\section{Michel Moatti*}

IRSA- CRI / Montpellier III

\section{Kinnik, a circulação digiłłal da violência}

A internet e, particularmente, sua filial críptica undernet (que corresponde, em resumo, à face escondida da rede: os fóruns, as salas de discussão gráficas como O Palácio, certos chatrooms, assim como os sites não-comerciais e difíceis de encontrar, já que não estão ligados por links aos portais) exploram com insistência os temas da violência, por vezes, associados aos da pornografia. Constata-se, analisando os usos coletivos da rede, como a undernet tenta se exonerar dos abusos e desvios comerciais que vampirizam a rede global. Ela reencontra assim as antigas utopias comuns nos primeiros anos de expansão de uma "rede das redes" vista como um instrumento formidável de redefinição das trocas e do comércio. Na undernet, com efeito, trata-se menos de vender que de dar, menos de negociar que de partilhar. Reafirmando superficialmente esses valores "ideais" dos anos 1960 ou 1970, a undernet propõe igualmente uma nova comunicação da violência, sobredeterminada pelo sentimento de fraternidade que parece circular entre os membros de certos domínios online.

Sarah Finger, que conduziu uma longa pesquisa sobre o fenômeno dos snuff movies $^{1}$ explica que, a maior parte do tempo, nas comunidades de interesse e de fantasia, o "material pornográfico (não era) produzido ou distribuído com fins comerciais". Observando os usos em vigor na undernet podemos constatar realmente que os usuários dos espaços de convivialidade e de convergência afetiva desviaram-se lentamente dos caminhos bem balizados da internet comercial. Como antigamente, quando experts e amadores sabiam se encontrar e trocar livros ou documentos, com seus pequenos segredos, em lugares ocultos e 
mantidos escondidos, as páginas verdadeiramente curiosas da rede colocam-se, de agora em diante, essencialmente na undernet: "esses amadores", explica ainda Sarah Finger, "procuram menos rentabilizar seus documentos que trocá-los com outros pervertidos" 2 .

Além disso, o aspecto comercial e mercantil do negócio passa para o segundo plano, ou mesmo se desfaz. Acolhendo benevolamente violência e pornografia - e, mais globalmente, todas as fantasias obscuras da alma humana - a undernet se afasta progressivamente da internet conquistadora, que atingiu seu apogeu entre 1998 e 2000, na qual novas tecnologias, ilusões, bolsa especulativa, ingênuos e raiders espertos faziam da rede uma coisa quimérica e instável. Preferindo o camarim à vitrine, a undernet subverte uns tantos procedimentos que tendiam a injetar os princípios liberais e especulativos - para grande lástima dos pioneiros idealistas da rede - e forçar a internet a virar uma simples sucursal de venda, afiliada às grandes marcas de fora.

Ao abrir o baile para as máscara e as identidades reconstruídas, a undernet não somente procura uma oportunidade para desmonetizar as paixões, mas, sobretudo, a obscura sub-rede inventa uma nova via de ruptura com a rigidez da existência social.

A undernet descomplexificou tanto novos libertinos como antigos libidinosos que são às vezes os mesmos, sob máscaras diferentes, apaixonados por bizarrices sexuais e por temas às margens da ordem social, em comunhão, sob os auspícios da violência, do excesso, da desmesura e da loucura. Instaurando a comunidade passional, declarando-a aberta às paixões mais insólitas, a undernet transforma em alcovas, confrarias e "ouvroirs de pairs" o sex-shop de fora, que encontra, nas avenidas da rede, novas entradas. As socialidades reinventadas da undernet são não somente "inapreensíveis" e "astuciosas", como Michel Maffesoli declara, propondo a chegada das comunidades emocionais, mas também complexas e múltiplas.
Contudo, a sombra produzida pela sub-rede undernet, e na qual ela dissimulase, terá, na sua passagem, carregado os fanáticos mais intolerantes com suas paixões ocultas e extremas, os perversos mais descontrolados, que, como anuncia Sarah Finger, encontram, nessa nova ordem, o lugar de todos os contatos e de todas as trocas. E singularmente, esta sub-rede terá aberto espaço para a expressão última de todas as encenações da violência.

Como motivações obscenas, próximas a contravenções penais mais graves e por isso protegidas como um segredo bem guardado (com efeito, trata-se muitas vezes da encenação entusiasmada de crimes, atrocidades e assassinatos, sem dúvida, próxima à apologia a toda natureza de transgressão), são capazes, no entanto, de espalhar-se e organizar-se nos domínios cibernéticos? Como conseguem suscitar adeptos, e mesmo inspirar vocações, reunir ao seu redor conjuntos de admiradores capazes, primeiro, de reconhecimento mútuo, e depois de trocas?

Por obsceno, não entendemos que estas figuras - descritas pelo primeiro exemplo que será dado, sob a forma narrativa de novelas - sejam apenas pornográficas. Algumas, aliás, não o são diretamente, na medida em que elas não se referem às representações do ato sexual. Os trabalhos de Kinnik, que serão expostos mais adiante (de ordem literária, que poderíamos qualificar provisoriamente como "ficcional"), são verdadeiramente obscenos porque eles rejeitam toda compaixão, toda humanidade, todo protocolo social. As personagens que compõem suas comédias humanas são, ou psicopatas torturadores, ou vítimas instrumentalizadas

Os universos paralelos de Kinnik são mundos de carrascos e de mártires. Os homens são, sem a menor dúvida torturadores de imaginação sem limites. As mulheres repartem-se em duas grandes categorias desiguais: dois terços de vítimas urrantes, que são humilhadas e têm sua carne massacrada; um terço de cúmplices mascu- 
linizadas, debochadas em sua indiferença ou loucura. Finalmente, entre os mártires, encontraremos sistematicamente em Kinnik um único alvo, constituído de crianças, essencialmente meninas.

Kinnik, nome ou apelido de um pornógrafo que atua online, acostumado aos fóruns e às listas de discussão que arquivam suas contribuições mais notáveis, como http://blackspectre.pornopartners.com/ sgstories.html ou http://assm.asstr.org/, reinventou e adaptou para a internet um sistema antigo e conhecido da sociologia: a corrente (tipo corrente da felicidade, ou corrente da maldição, se ela vem a ser quebrada). Hábil variação em torno do procedimento do hipertexto, a presença de Kinnik na internet se advinha, se presume (por exemplo na origem de certas séries de post/repost em alguns fóruns), em vez de se afirmar num lugar qualquer de convergência onde se encontrariam os membros.

Kinnik não possui sequer um site pessoal, ou outro lugar constante de exposição; ele não propõe nenhum espaço de encontro ou de confronto para seus leitores e admiradores. A presença de Kinnik não pode ser observada aqui ou lá, mas sempre no desvio e, forçadamente, em atraso. Desse modo, qualquer um - discípulo, bajulador ou fanático - já a terá tocado, pressentido ou cruzado por ela. Veremos mais adiante que Kinnik reinventa também o mito da presença maléfica, onipresente sem jamais estar em algum lugar, flutuante, inapreensível... Não se pode deixar de supor sua real existência, nem jamais excluir a possibilidade de uma duplicidade ou de um mito. Como uma divindade que apenas alguns felizardos e raros eleitos puderam encontrar, durante visitas quase miraculosas. Kinnik só sobrevive porque outros reinscrevem permanentemente as provas de sua passagem e dos traços de sua obra.

A corrente assim concebida assemelhase então a um processo de micro-iniciação, repetida ao infinito, visando constantemente restabelecer novos adeptos, substituindo aqueles que se evaporaram no ciberespaço.
Os endereços de encontros são furtivos, os sites e contribuições sobre os newsgroups dedicados à obra de Kinnik são voláteis; o segredo sobre o epicentro, sobre a localização, sobre a hierarquia provável, em todo caso, sobre o iniciador e inventor do fetiche, segue extremamente bem guardado. O próprio Kinnik nunca aparece fora de sua assinatura abaixo de seus escritos originais. Em nenhum lugar aparece uma coordenada que lhe diga respeito, nem mesmo o incontornável endereço de e-mail, que acompanha tradicionalmente as contribuições online.

Os discípulos parecem dedicados unicamente à circulação dos seus escritos, sua difusão e sua permanência na rede. Os textos - pouco numerosos - de Kinnik (três, sem dúvida, são autênticos; dois, surgidos mais recentemente nos arquivos dos fóruns indexados pelo Google são duvidosos ${ }^{3}$; uma meia dúzia de outros são imitações ou trabalhos "à moda de...") são publicados online regularmente por seus admiradores, sem a menor mudança. Nesse universo cibernético, onde a forma depende de um certo número de regras técnicas concernentes às tipografias, às justificações, às quebras de linha, etc.), a reapresentação quase idêntica dos mesmos textos é uma proeza e prova a veneração que os adeptos têm por Kinnik.

A organização do seu desaparecimento ou de sua invisibilidade face aos curiosos é perfeitamente assumida por Kinnik e seus seguidores. Kinnik queima sutilmente as pistas e simplesmente recusa-se a aparecer pessoalmente. Não se registra quase nenhuma aparição pública desde 1999 com seu (apelido) nome, abstraindose a duplicação de páginas antigas sob nova data. Mas suas contribuições continuam a ser exploradas e consultadas na rede: graças a um sutil jogo de procuração que ultrapassa a simples utilização do regime de pseudônimos, habitual na internet, Kinnik difunde e explora sua reserva de textos. Adeptos (ou heterônimos?), que não teriam desaprovado o apagador de pistas e identi- 
dades que foi Fernando Pessoa, duplicam sem descanso sua grande obra e mantêm sempre atualizado seu catálogo ${ }^{4}$. $\mathrm{O}$ mais inflamado deles (o ponto de que é provável que se trate do próprio Kinnik), Master Sardu, derrama em pequenas doses os "grandes" textos de Kinnik e faz ininterruptamente referência a uma novela quase mítica entre seus admiradores (New Dawn), que ninguém realmente leu, mas que circularia há mais de três anos sob as rotas negras da undernet. Lá, estamos em um domínio conhecido da literatura onde bibliografias não-oficiais coabitam com os traços oficiais, e onde "iniciados" dizem ter lido ou acessado paginas inéditas ${ }^{5}$. Seja como for, o sistema Kinnik evoca realmente uma mecânica da proteção e da dissimulação, onde coexistem, em permanência, uma irrefreável vontade de ser lido e de não ser visto ou localizado. Existe ali um paradoxo forte, que insiste sobre as oscilações da visibilidade e do segredo na internet, onde desejase ao mesmo tempo ser conhecido, até reconhecido, e continuar escondido. Kinnik, organizando sua ubiqüidade, sua perpétua ressurreição sob novas máscaras e novas identidades, pretende reinicializar continuamente seu trabalho. Escondido nas dobras herméticas da undernet, confia a um batalhão de lacaios, ou a seus duplos heterônimos, a missão de ressuscitar sua obra e a si próprio. Fantasmas ou $\mathrm{Fu}-\mathrm{Manchu}$, príncipe oculto do mal e do maléfico, escondido na sombra da undernet, ele não reside em nenhum lugar, mas intervém em todo lugar, mantendo-se exterior às requisições penais que sua obra - mesmo sendo de pura ficção - sem dúvida justificaria.

\section{O protocolo Kinnik}

Antes de descrever o sistema Kinnik e o estilo da sua produção ultraviolenta, apresentamos as primeiras linhas da novela intitulada "Anne".

Enviada e multienviada sob diferentes formatos e a partir de variados nomes de remetentes - mais de 15 versões diferentes circulam desde 1999, o mais antigo "traço" da produção Kinnikiana online - essa narrativa sórdida coloca em cena o rapto, o estupro e o assassinato de uma criança de dez anos por dois psicopatas.

O tom da narrativa é do tipo clínico, sem intervenção do autor para tentar colorir emocionalmente a história. Os dois criminosos nunca são apresentados de maneira empática; a vítima é descrita como um simples acessório. O relato é enviado com uma breve apresentação:

Kinnik has asked me to post these stories ("Anne", "Park" and "Fourteen"). They are simple-plotted, straight-forward tales of misogyny and murder. Some of you may know him through his earlier piece "New Dawn".

O estilo dá a entender claramente que Kinnik não é quem envia a novela ao fórum. Ignora-se se o autor utiliza um grande número de pseudônimos ou se admiradores de sua obra se satisfazem ao proporcionar uma maior abrangência a um trabalho que eles julgam admirável e que mereceria repercussão e difusão maiores.

Seguem ainda essas linhas de advertência, que, ao lado dos cuidados legais, sugerem a dimensão fraternal e comunitária do lugar, que funciona graças às doações

\section{STANDARD DISCLAIMER: WARNING!}

The following story contains graphic depictions of snuff, extreme violence, rape, torture and murder.

http://www.asstr.org, an entity supported entirely by donations.

Em seguida o texto mesmo:

Gary $^{6}$, o maior dos dois homens, se colocou atrás da menina do dia. Ela tinha em torno de dez ou onze anos, loira e bronzeada, os olhos amendoados e um rosto de anjo. Ela o 
fixava com terror. Ela ainda não tinha dito uma palavra, mais se via bem que tinha compreendido perfeitamente que estava numa grande enrascada.

- Como tu te chamas, coração?

- Anne, murmura ela.

- E qual é a tua idade?

- Dez anos.

- Bem. Você parece uma menina inteligente, Anne. Você já sabe alguma coisa a respeito de sexo?

Ela balança negativamente a cabeça: ela sabia o suficiente para começar a temer as implicações dessa questão.

- Muito bem. Porque é justamente disso que se trata. Meu amigo e eu, nós vamos te violentar!

Gary observa que ela tenta não chorar. Nada mal para uma menina de dez anos, pensa ele.

- Você sabe o que quer dizer violar, coração?

Ela balança a cabeça. Ele se pergunta se ela realmente ignora o sentido da palavra, ou se isso faz parte dessa meia-consciência que as crianças têm pelas coisas do sexo.

- E sobre a morte? O que você sabe sobre a morte?

Ele pergunta sorrindo. Dessa vez, as lágrimas rolam pelo seu rosto. Ela sacode freneticamente a cabeça.

- Uau! Você é realmente uma mocinha. Você conhece essas coisas muito bem. Porque é justamente isso que vai te acontecer hoje. Quando tivermos te violentado de todas as maneiras que quisermos, nós vamos te matar. $\mathrm{Na}$ verdade, provavelmente te mataremos enquanto estivermos te violentando. E talvez te violaremos ainda depois de te matar. Mas tudo isso dá no mesmo. Você vai sofrer, e depois vai morrer...

E nunca mais verá seus pais...

Evocamos acima o sistema elaborado por Kinnik para difundir sua obra, colocando como hipótese provável, confirmada vá- rias vezes durante as entrevistas no alt.tasteless, que ele jogava com dois mecanismos: uma publipostagem ou multi-postagem, efetuada por ele mesmo com apelidos variados e efêmeros, dos mesmos textos (Anne, Park, e Fourteen, mais os dois "duvidosos" que totalizam, segundo nossas estimativas, em torno de $60 \mathrm{mil}$ signos, ou seja, um pouco mais de nove mil palavras), colocada online por terceiros, encarregados ou não por Kinnik de difundir esses trabalhos. Estes poderão ter títulos diferentes ou ser por vezes parcialmente reescritos, resumidos ou retrabalhados. Pode acontecer eventualmente que desenhos pornográficos sejam anexados aos textos, sem que seja possível dizer se eles foram realmente inspirados no trabalho literário que acompanham.

Os textos de Kinnik parecem ter sido colocados online primeiramente em http:/ / www.asstr.org, e em seguida duplicados em uma dezena de fóruns, como alt.sex.stories.moderated, e alt.sex.stories. Encontramos traços de uma primeira entrada online de certos textos de Kinnik desde janeiro de 1999, mas os mesmos textos foram duplicados de maneira extremamente cuidadosa desde então, e figuram daí em diante nas listas destes newsgroups. Como que para lutar contra o envelhecimento contínuo - e, enfim, o desaparecimento dos materiais online nos domínios não-comerciais da rede, Kinnik e seus ajudantes republicam sem parar os textos em vias de desaparição, e asseguram sua perenidade na undernet.

Existe realmente uma vontade não solitária (visto que as dimensões da transmissão parecem incompatíveis com os esforços de um só homem), mas coletiva de guardar rastros e possibilidades de acesso a um material hiperviolento, anti-social, e desviante, ao qual esse grupo dá uma importância toda particular. A dimensão, a extensão dessa comunidade Kinnikeana, é difícil de avaliar. Grupo microscópico, composto de algumas dezenas de indivíduos disseminados aqui e ali no mundo, ou uma fraternidade mais importante? Em 
todo caso, trata-se de um grupo, organizado, estável, e suficientemente solidário para gerar a idéia de disponibilização e conservação de rastros.

A respeito de Kinnik e seus textos, nossa hipótese é que a violência e a obscenidade do propósito seriam mais adequadas a um tipo de prazer solitário e secreto, sujeito até mesmo a sentimentos de culpa e vergonha. Nesses processos de partilha e de consumo coletivo, então, forma-se uma conjuração do inaceitável.

O sistema instaurado por Kinnik tomou implícita e progressivamente, entre alguns internautas, o nome do seu "inventor", sem que o autor o tenha necessariamente desejado. Tanto que, como explica MR HYD3 (Mr Hyde), essa mecânica da postagem e da multi-postagem, efetuada sob pseudônimos diferentes, mas sempre citando o autor, resultando em uma espécie de impregnação de seu nome, junto com forte reconhecimento, a ponto de o sistema receber, em certos domínios da undernet, o nome de "protocolo Kinnik":

Kinnik certamente enviou seus textos dezenas de vezes com diferentes pseudônimos. Em todo caso, no alt.tasteless, eu vi o vi encaminhar por meses, seja Anne ou Park... As indicações do autor (ele mesmo!) ficavam claras. Aí ele fez algo que é profundamente intolerável, uma espécie de spaming. Só que como ele agia, arrisco dizer, enviando material "interessante", ninguém disse nada. Ao contrário. Pedíamos mais, demos continuidade a seu trabalho. Um golpe de gênio, na minha opinião. Ainda falamos às vezes no tasteless sobre "o protocolo Kinnik", mas ninguém que eu conheça conseguiu fazê-lo como ele ${ }^{7}$.

$\mathrm{O}$ fato de se consumir e apreciar em grupo essas motivações excêntricas e secretas, de se estar ao lado de outros entusiastas ou neófitos, permite que se amenize uma certa carga de culpa. Excitar- se com as narrações de estupro de uma menina, com o desenrolar detalhado de seus tormentos e de sua morte por dois brutos inescrupulosos, torna-se sem dúvida menos repugnante, e possibilita a salvaguarda de uma certa imagem de si, que seria profundamente degradada pela consciência do consumo secreto e solitário desses temas. O segredo, colocado em comum nas dobras da undernet, torna-se então uma maneira de livrar-se da responsabilidade de um ato, mesmo que alguns de seus autores classifiquem-no como degradante e anti-social. Ressocializar esse ato, por intermédio da partilha entre iniciados, torna-o menos expressivo, menos obsceno, menos dramático.

\section{Brunerie, a violência com॰ apel॰ a๑ outro}

O exemplo que segue explora a utilização da internet para o desvendamento de um segredo intimamente ligado à violência. $\mathrm{O}$ exemplo coloca igualmente em evidência um dos aspectos do segredo, evocado por Georg Simmel, e retomado por Georges Balandier: a função discriminatória que o segredo pode ter em determinadas circunstâncias. O segredo, afirma Georges Balandier, "contribui para uma dinâmica desigual entre iniciados e não-iniciados" ${ }^{\prime 8}$.

No dia 14 de julho de 2002, um desconhecido, Maxime Brunerie, tentou assassinar o presidente da República francesa durante o desfile no Champs-Élisées. Naquele momento, ninguém sabia ainda que se tratava de um ato não somente premeditado (como a aquisição da arma pouco antes da execução do gesto deixara claro aos investigadores), mas inclusive que o ato havia sito anunciado publicamente. Ainda que considere-se que o anúncio tenha sido feito de maneira encriptada e, sem dúvida, unicamente compreensível, naquela hora, aos iniciados ou companheiros do autor da tentativa de assassinato.

Com efeito, na véspera do desfile de 
14 de julho em Paris, Maxime Brunerie, um jovem "neonazi" de 25 anos, membro da facção U.R., União Radical, enviara, a um fórum indexado do site britânico "COMBAT 18 BLOOD AND HONOUR", uma mensagem lacônica assim redigida:

Nome: Maxime

De: Paris

Sent: 13:01 GMT on 13 July

"Watch the Tv This Sunday, i will be the star... Death to zog, 88! "10

Zog é um acrônimo freqüentemente utilizado nos sites anti-semitas, prófascistas ou neonazis, que significa "Zionist Occupation Governement" (Governo de Ocupação Sionista), ou seja, no jargão confuso dos supremacistas brancos, uma referência aos regimes democráticos ocidentais. Quanto ao número " 88 ", ele representa a transcrição - também bastante conhecida nos meios de extrema direita - do desdobramento da letra " $\mathrm{H}$ ", oitava letra do alfabeto, e quer dizer "Heil Hitler".

O que é realmente interessante neste caso é que um indivíduo, a ponto de cometer um ato de extrema gravidade anuncia sua intenção 24 horas antes de passar à ação. Essa gravidade coexiste - e seja qual for o perfil psiquiátrico rapidamente evocado pelos investigadores - com uma plena consciência, já que Maxime Brunerie declarou querer "provocar uma crise do regime matando o presidente da República" antes de "dar fim aos (seus) dias".

O outro ponto totalmente singular da história é o segundo objetivo ligado a este ato extremo, a missão implícita que ele se confiou: o atirador queria "que se falasse dele", desejava "ser uma estrela", como escreveu no guestbook do site "Blood and Honor" na véspera do desfile.

A mensagem no fórum " COMBAT 18 BLOOD AND HONOUR ", registrada, mas não formalmente identificada pelos serviços da polícia britânica, foi transmitida aos investigadores franceses na noite mesmo do atentado. A questão evidentemente colocada, tanto pelos investigadores da polícia como pelos jornalistas, foi a seguinte: por que o autor de uma tentativa de assassinato premeditado confiou, à incrível transparência do espaço público da internet, uma intenção tão grave e espetacular, para a qual o segredo em torno de sua preparação e sua execução apenas garantiria uma ínfima chance de sucesso?

A resposta freqüentemente proposta ficou parcialmente encoberta pelo lado "criptografado" do anúncio: o código obscuro, impenetrável e enigmático não poderia atrapalhar de maneira significativa a boa realização da operação, e era, segundo certos investigadores, apenas uma espécie de provocação sem risco real, típica destas personalidades patológicas. Ela não seria nada mais que uma manifestação de uma espécie de orgulhosa fanfarronice, comparável àquelas feitas pelos os "malvados" e outras "encarnações do mal" em certas obras romanescas ou cinematográficas, e que leva-os, de maneira estúpida, a deixarem suas futuras vítimas - que são evidentemente em geral os "heróis" da história - a cargo de suas maquinações e de seus projetos. Fanfarronices que costuma conduzi-los, claro, diretamente a sua derrota e, enfim, a sua ruína.

Abrindo o segredo, mas só até a sua metade, ou seja, abrindo-o de maneira criptografada, codificada, obscura e velada, Maxime Brunerie enquadra-o bem neste aspecto, nesta esta função discriminatória que o segredo às vezes possui. De fato, o neonazi Maxime Brunerie, extraviado solitário nas ligações faccionais, não revela (ou não pretende revelar) seu segredo para além de seus pares, dos outros iniciados da esfera subversiva européia, agentes conhecedores dos códigos secretos do neonazismo, das terminologias cifradas, dos símbolos e criptogramas, que, de "Zog" a "88", difundem suas mensagens e seus diálogos.

“Toda asserção pública é criptograma e mentira", lembra Alexandre Koyré. As verdadeiras mensagens devem se endereçar - ao fundo - apenas aos "iniciados e 
àqueles que são dignos de o serem. Eles compreenderão, decifrarão e perceberão o véu que mascara a verdade"11.

Assim, "Watch the Tv This Sunday, I will be the star... Death to zog, 88!" pode vir a ser, para quem sabe, muito mais permeável e muito menos obscuro. Considerando-se a origem francesa da mensagem, a data (domingo, 14 de julho) e a repercussão considerável que o autor espera, ela torna-se bem menos ilegível e pode levar qualquer leitor, mesmo de espírito pouco dedutivo, a desconfiar que uma investida espetacular, sem dúvida violenta, acontecerá na França contra a República ou seus representantes.

Endereçar-se inteligivelmente apenas aos pares é precisamente um dos modos de funcionamento das comunidades e sociedades secretas: os camaradas, os companheiros são os únicos que procuramos encontrar, convencer, seduzir. Os outros ficam por fora do círculo de inteligência.

Berger e Luckman consideram, no que diz respeito a esse afastamento, a esse impedimento a que estão circunscritos os comuns mortais (os profanos) diante dos universos secretos, que "o número crescente de subuniversos e suas complexidades os tornam sempre acessíveis aos profanos. Eles convertem-se em enclaves esotéricos "selados hermeticamente (no sentido clássico do corpo hermético do saber secreto) para todos, exceto para aqueles que foram adequadamente iniciados aos seus mistérios ${ }^{\prime \prime 2}$.

Esse modelo encontra evidentemente um meio operatório particularmente propício entre comunidades ligadas à violência, à agitação e à agressão.

Esse aspecto da internet, utilizando a cifragem e o código, e favorecendo as alianças ocultas entre iniciados e membros de facções que procuram proteger suas ações, como reuniões, foi perfeitamente observado por Dan Velea em seu trabalho sobre as comunidades da rede: "Os novos espaços de discussão e de vida substituem os IRC. O fenômeno da undernet - internet underground - ilustra de uma maneira pertinente os ritos iniciáticos e a proteção de seu espaço. Os internautas reagrupam-se nestes locais da undernet segundo um protocolo fechado, que permite a troca de idéias apenas entre os membros do mesmo grupo. $\mathrm{O}$ fato de trocar freqüentemente de endereço http seria uma proteção suplementar contra os não-iniciados, os curiosos e, numa etapa superior, as autoridades"13.

No que diz respeito a essa última suposição, vimos que, desde a véspera da interdição do site da Unité Radicale, por decisão tomada em Conselho de Ministros na quarta-feira, dia 7 de maio, o site havia mudado de endereço http e de host. As ofertas de ajuda ao atirador do ChampsÉlyées já tinham sido feitas e transmitidas. As contribuições tiveram a identificação de seus autores suprimida e foram transcritas fielmente (como todas as citações de sites e fóruns reproduzidas neste artigo):

\section{Ajuda a Maxime}

Autor: Frank K. (一.abo.wanadoo.fr)

Data: 20-07-02 00:06

Não me refiro a motivações ou justificativas deste ato trágico...

A partir de informações seguras, sabemos que os pais de Maxime não partilham suas idéias políticas, e sem falar de sua irmã que namora com um... O problema é o seguinte: se nós vamos ajudar Maxime (e devemos fazê-lo!), é impossível passar por sua família pelas razões enumeradas acima. Que fazer? O hospital onde ele está atualmente (em Villejuif) me desligou o telefone "na cara" assim que citei seu nome... Ele tem um advogado? Devemos contatá-lo? O CEPE tem meios para "contornar" os obstáculos?

$\mathrm{Na}$ imprensa, não tem mais nenhum traço, nenhum comentário. Pouco importa a aprovação ou reprovação de seu gesto: não esqueçamos Maxime Um camarada da Essonne.

Re: Ajuda a Maxime 
Autor: Franck W. (-.cvx28bradley.dialup.earthlink.net)

Data: 21-07-02 07:38

Eu sou outro Franck. Eu sou americano, mas me dedico à luta francesa. Eu concordo que devemos ajudar $\mathrm{M}$. Brunerie. Como podemos fazer isso daqui? Se não existe nenhum grupo aqui para ajudá-lo, devemos criá-lo. Será que alguém conhece um advogado nacionalista na França que possa oferecer seus serviços?

Maxime Brunerie, uma personalidade cinza, sem gosto, sem relevo e sem laços afetivos profundos ${ }^{14}$, como descrevem num conjunto perfeito seus antigos colegas de escola ou do serviço militar. Ao anunciar com antecedência ${ }^{15}$ seu ato, ao encenar sua agressão, comunicando a priori a violência de um ato que virá, ele procura, antes de tudo, aprofundar suas relações com o outro, afirmar seu perímetro relacional. Ele faz isso insistindo sobre o que pode confirmar e fortificar o único elo comunitário que conhece: a violência que domina o interior das facções neonazistas. Que melhor fermento que ser o "herói", aquele que terá dado fim a um regime vergonhoso, de maneira bem mais radical que aquela do veredicto das urnas (pouco legítimo aos olhos dos totalitários do U.R. - e que vem de se descredibilizar ainda mais a seus olhos no momento das recentes consultas eleitorais)?

Pois se Maxime Brunerie possui alguns colegas de militância, tem na verdade poucos amigos. E que melhor ocasião para descobri-los ou inventá-los - no seu universo de pertinência - do que colocando-se como aquele que foi capaz de "mudar o mundo"16 violentamente, segundo as visões e esperanças da facção?

$\mathrm{O}$ sistema descrito por Jean-Noël Kapferer evoca a procura de prestígio e do ganho de relevância social empreendida por aquele "que faz uma confidência e permite a partilha de um segredo" e que "sai glorificado por essa transação" 17 .

Com efeito, a partir do conhecimento da ação do atirador, informações sobre ele são repassadas na rede dos sites ligados aos movimentos da extrema direita européia, e Maxime Brunerie é elogiado, felicitado, condecorado sob o título de "glorioso soldado branco".

$\mathrm{Na}$ nebulosa das extremas direitas, Maxime Brunerie, que era apenas uma minúscula poeira negra, torna-se, graças a seu gesto, um astro menor que brilhará por algumas das horas de um luar doentio.

O gesto - mas também o anúncio feito antes, numa rede afinitária - demonstra bem sua intenção, que é a procura de laços cúmplices. O próprio excesso do gesto e das suas justificativas teóricas assegura a pertinência deste quadro.

Procura-se por ele nos motores da internet, interroga-se sobre sua vida, suas relações, suas crenças; seus novos amigos, jovens nazistas na maior parte, publicam "mensagens de apoio à Maxime".

Citamos algumas delas como ilustração, o que parece-nos dar um pouco mais de corpo e de realismo - em seus excessos a nossa análise. Reproduzimos as mensagens publicadas no fórum "COMBAT 18", erros e acrônimos incluídos:

Name: Paolo

From: France

Sent: 20:08 GMT on 16 July

We are with you my camarade Maxime, here in France we'll never forget your name.

Saudações nacionalistas.

Name: souska

From: lebanon

Sent: 14:00 GMT on 16 July

long live maxime, white pride world wide

Name: Lilith88

From: France

Sent: 12:26 GMT on 16 July

I don't know if trying to shoot at the 
president was a good idea, but we are behind you, Maxim ! Sieg Heil Viktoria ! Heil Hitler !

Name:A França aos Franceses

From: France

Web address: www.kob.fr.st

Sent: 11:31 GMT on 16 July

Sieg Heil Maxime Brunerie ! Não te esqueceremos jamais !! MORTE AOS ARABES!!MORTE AOS NEGROS !! WHITE POWER 14/88 A França aos franceses !!!!!!

Name: tazzz

From: paris

Web address: www.mort-aux-rg.com

Sent: 6:46 GMT on 16 July

A queda de um peão não é suficiente para ganhar a partida...

APOIO A MAXIME POR UM MUN-

DO MELHOR. 88HEIL HITLER88 666HAIL SATAN666

Paciência... justiça será feita em alguns meses, paciência...

Name: syd 88

From: Europe

Sent: 18:38 GMT on 15 July

Para uma nova ordem mundial Mort a

ZOG 88! Apoio a Maxime

Name: Walking Time Bomb

From: England

Sent: 21:08 GMT on 14 July

Its a shame that the White Warrior in France missed his target. Lets see some more Patriots making a stand. Hail David Copeland ${ }^{18}$ !

\section{Notas}

Texto traduzido do francês por Clélia Pinto

* Professor de Sociologia na Universidade Paul Valéry Montpellier III. Doutor em Sociologia pela Universidade Paul Valéry - Montpellier III. Pesquisador no Institut de
Recherches Sociologiques \& Anthropologiques e no Centre de recherches sur l'Imaginaire. Contato: michel.moatti@univ-montp3.fr

1 Filmes clandestinos, nos quais os atores e atrizes seriam realmente levados à morte na frente das câmeras. São realmente considerados como snuff movies aqueles nos quais a morte é dada intencionalmente e que não visam o lucro financeiro. No momento atual, Sarah Finger conclui que nenhum snuff não pôde, seja pelo FBI ou pela Interpol, ser considerado autêntico.

2 FINGER, Sarah. La Mort en Direct, Snuff Movies. Paris: Le Cherche midi éditeur, 2001, p.169

3 The black boy gets the white girl e Rape of the schoolgirl

4 Por exemplo em http://assm.asstr.org/

5 Pensamos evidentemente neste outro amante de heterônimos, o Belga Raymond-Marie, de Kremer, em literatura, Jean Ray para a parte francófona de sua obra, e John Flandres para a parte flamenga, que se deleitou ao queimar as pistas de sua própria bibliografia, em particular colocando na capa de seu primeiro livro uma referência a outro título "Do mesmo autor" evidentemente fictício, e que tornou-se lendário, Terra de Aventuras. E também, em Borges, que se satisfez em permanentemente misturar o verdadeiro e o falso, as obras "visíveis e invisíveis"...

6 Tradução pessoal.

7 Entrevista, outubro 2002, MrHyd3, em alt.tasteless.

8 BALANDIER, Georges. L'anthropologue, ses secrets et ceux de l'Autre. In: PETITAT, André (dir.). Secret et lien social. Paris: L'Harmattan, 2000, p. 19.

9 http://www.skrewdriver.net/index2.html, e pelo fórum: http://drypool.net/cgi-bin/system.pl?id=isdgb\&cmd=p.1

10 No dia 15 de julho, encontramos no mesmo fórum essa mensagem interrogativa:

"From:NM/ nm@telegraph.co.uk

To: b\&h/combat18 Sent: Monday, July 15, 2002 11:12 AM

On your guest $\mathrm{p}$. today there is a message from Maxime, who attempted to assassinate Chirac yesterday. He ends his message with death to zog, 88! What does this mean 
and what do yout think of his assassination attempt?" Trata-se de uma mensagem escrita por uma jornalista do Telegraph de Londres, Nicole Martin, vindo "procurar informações" sem grande discrição, e que seria severamente repelida. Da mesma maneira, várias mensagens deixam em alerta os membros habituais do site, que pediam discrição sobre 0 grupo e suas atividades. Solicitação ambígua, evidentemente, já que a visibilidade de Blood\&Honour parecia ainda garantida sobre a rede.

11 KOYRÉ, Alexandre. Réflexions sur le mensonge. Renaissance. New York: jan-mar 1943. In: Topos, http:// perso.wanadoo.fr/espace.freud/topos/psycha/ psysem/mensonge.htm

12 BERGER, Peter; LUCKMAN, Thomas. La construction sociale de la réalité. Paris: Méridiens Klincksieck, 1992, p. 121.

13 VELEA, Dr Dan. Cyberaddiction et réalité virtuelle. In: http://psydoc-fr.broca.inserm.fr/hometox.html

14 A personalidade de Maxime Brunerie lembra aquela de Richar Durn, o assassino do conselho municipal de Nanterre. No dia 26 de março de 2002, este tomou consciência do fracasso de suas militâncias (nos movimentos humanitários), sem saída para sua integração social e comunitária.

15 Como certos artistas de circo, particularmente hábeis ou seguros de seu ato anunciam o desenrolar perfeito e exato de seu "número".

16 "I want to change the world and you have to start by changing the regime." (Eu quero mudar o mundo, e é preciso começar mudando o regime), justificativa de Maxime Brunerie aos policiais no momento de sua prisão, Charles Bremner, The Time, July 15, 2002.

17 KAPFERER, Jean-Noël Kapferer. Rumeurs: le plus vieux média du monde. Paris: Seuil, 1987, p.26.

18 David Copeland é o jovem de 23 anos responsável por uma série de atentados a "bomba a prego" que fez três mortes e várias dezenas de feridos em bares freqüentados pelas comunidades judaicas, antilhesas e homossexuais em 1999 em Londres.

Com um perfil psiquiátrico próximo ao dado a Maxime Brumerie, Copeland foi condenado à prisão perpétua.

\section{Referências}

BARTHES, Roland. Sade, Fourier, Loyola. Paris: Points - Seuil, 1971.

BAUDRY, Patrick; SORBETS, Claude; VITALIS, André (Dir.). La Vie privée à l'heure des médias. Presses Universitaires de Bordeaux: Labyrinthes, 2002.

FRAU-MEIGS, Divina. Médiamorphoses américaines. Paris: Économica, 2001.

GABEL, Joseph. Sociologie de l'aliénation. Paris: P.U.F, 1970.

JEAY (Anne-Marie). Les Messageries télématiques, Paris, Eyrolles, 1991.

MOATTI, Michel. La Vie cachée d'Internet. Paris: Imago, 2002.

_. Une violence virtuelle. In: Violences médiatiques, Contenus, dispositifs, effets. Paris: L'Harmattan, 2003.

SIMMEL, Georg. Secret et sociétés secrètes. Paris: Circé/poche, 1996

SULER, John. Psychology of Cyberspace/Life at The Palace. New Jersey: Rider University,1997. In: www.rider.edu/ users/suler/psycyber/psycyber.html 